\title{
COMPARATIVE EVALUATION OF THE EFFECTS OF SILVER DIAMINE FLUORIDE (COMMERCIAL AND LAB PREPARED) VERSUS NANO SILVER FLUORIDE ON DEMINERALIZED HUMAN ENAMEL SURFACES (IN VITRO STUDY)
}

\author{
Asmaa Aly Abo El Soud*, Heba Abdulfattah Elsaied** \\ and Shaimaa Mohamed Mahfouz Omar*
}

\begin{abstract}
Background: - To evaluate and compare the effects of Silver diamine fluoride (commercial and lab prepared) versus nano silver fluoride on demineralized human enamel surfaces. Materials and methods: - A total 20 Extracted premolars for orthodontic reasons were collected from the Outpatient Clinic of surgical Department, Faculty of Dentistry, Suez Canal University. Each premolar was sectioned buccolingually into two halves, to obtain (40) specimens. These halves were randomly allocated into 5 groups according to different treatment modalities. Group I included 8 specimens were left untreated (negative control), Group II included 8 specimens were treated with demineralizing solution, Group III included 8 specimens were treated by Silver diamine fluoride (commercial form) after demineralizing solution, Group IV included 8 specimens were treated with Silver diamine fluoride (lab prepared) after demineralizing solution and Group V included 8 specimens that were treated with Nano silver fluoride after demineralizing solution. Each half was evaluated by Environmental scanning electron microscope and Energy dispersive x-ray spectroscopy .
\end{abstract}

Results: There were significant differences between groups at P-value $(\leq 0.05)$ for Phosphrous, Calcium and Calcium/Phosphrous ratio except (Fluoide). The lowest value for elements was recorded in group (II) followed by control group and the highest value was recorded at group (V).

Conclusion: Silver Diamine Fluoride (lab made) is as efficient as commercial one in remineralizing demineralized enamel surfaces. Nano Silver Fluoride is more efficient than Silver Diamine Fluoride (lab made \& commercial) on demineralized enamel surfaces.

\footnotetext{
* Lecturer Pediatric and Preventive Dentistry and Dental Public Health, Faculty of Dentistry, Suez Canal University ** Assistant Professor Oral Biology Department, Faculty of Dentistry, Suez Canal University.
} 


\section{INTRODUCTION}

Dental caries is an infectious microbiologic disease of the hard tissues. ${ }^{(1-3)}$ It is a worldwide public health problem disturbing numerous communities. ${ }^{(4)}$

Dental caries develops from a cycle of demineralization and remineralization with several stages being either reversible or irreversible. It is started through demineralization of tooth hard tissue by organic acids created from fermentable carbohydrates by cariogenic bacteria that presents within dental plaque. ${ }^{(4)}$

Fluoride is the most commonly used remineralizing agent. As the $\mathrm{pH}$ of saliva rises, new and larger crystals that contain more fluoride (fluorapatite) formed, thereby reducing the enamel demineralization and enhancing remineralization..$^{(5,6)}$

Silver diamine fluoride (SDF, $\mathrm{Ag}(\mathrm{NH} 3) 2 \mathrm{~F}$ ) has been proven to acquire antibacterial action that inhibits caries progression via stopping biofilm formation and helping enamel remineralization ${ }^{(7)}$ SDF has been established to be active for caries reduction in cavitated primary teeth and first permanent molar in 6-year old school children during a 36-month study. ${ }^{(7)}$

The anticariogenic effect of Silver diamine fluoride (SDF) [Ag (NH3)2F] is to releases fluoride ions quickly, therefore, assisting enamel remineralization. SDF is recommended by dentists to prevent the progress of caries mostly in Japan, Australia, and the United States. The product was cleared for sale in the United States in August 2014 by the Food and Drug Administration as a class II medical device.

SDF increases the resistance of demineralization, this occurs by formation of silver phosphate on enamel and enhancement of absorption of fluoride into dentin. This leads to blockage of dentinal tubules with further rises of minerals in peri and inter tubular dentin. ${ }^{(8)}$
Fluoride and silver in (SDF) interact with hydroxyapatite in tooth structure to form calcium fluoride and silver phosphate, which increase mineral density of enamel, increase the hardness of hydroxyapatite crystals, and decrease the depth of the carious cavity. ${ }^{(9,10)}$

Today, Silver diamine fluoride can be prepared in lab to be available for arresting caries by simple, non-invasive, and low-cost medication.

Nano silver fluoride (NSF) is introduced as an alternative to silver diamine fluoride (SDF) in caries prevention, the main reason for that, is despite the ability of SDF in preventing and arresting caries e ven when applied once a year, it has some disadvantages such as black staining of carious tissue and metallic taste ${ }^{(11-13)}$.

In vitro study was conducted on 2017 to determine the impact of Nano- Hydroxyapatite (NHAp), Nano Silver Fluoride (NSF) and Sodium Fluoride $(\mathrm{NaF})$ varnishes on enamel remineralization, it was revealed that both $\mathrm{NaF}$ varnish and NHAp had similar effect in remineralizing initial enamel caries and that NSF have the greatest remineralization capability in comparison to the other two materials evaluated. ${ }^{(14,15)}$

Until now From our knowledge's there is no study that evaluate and compare the effects of silver diamine fluoride commercial and lab prepared versus nano silver fluoride on demineralized human enamel surfaces. The null hypothesis was that there is no difference in remineralizing effect of these materials.

\section{AIM OF THE STUDY}

The aim of study was to evaluate and compare the effects of silver diamine fluoride (commercial and lab prepared) versus Nano sliver diamine fluoride on demineralized enamel surfaces (in vitro) by:

1- Environmental scanning electron microscope (ESEM). 
2- Energy dispersive x-ray spectroscopy (EDX) study presented in table (1): for assessing minerals content .

\section{Ethics}

\section{MATERIALS AND METHODS}

\section{I -Materials}

The present study was approved from the

The materials and instruments were used in this Research Ethics Committee, Faculty of Dentistry, Suez Canal University code (205/2019).

TABLE (1): Materials brand names, composition and manufacturers:

\begin{tabular}{|c|c|c|}
\hline Materials used in the study & Composition & Manufacturers \\
\hline $\begin{array}{l}\text {-Silver diamine fluoride } \\
\text { (commercial form) concentration } 44.800 \\
\text { p.p.m fluoride }\end{array}$ & $\begin{array}{l}\text { Diamine Silver Fluoride } 8 \% \text { solution } \\
\mathrm{Ag}\left(\mathrm{NH}_{3}\right) 2 \mathrm{~F}\end{array}$ & $\begin{array}{l}\text { TEDEQUIM S.R.L } \\
\text { Cordoba, Argentina }\end{array}$ \\
\hline $\begin{array}{l}\text {-Silver diamine fluoride } \\
\text { (Synthetic form) concentration } 44.800 \\
\text { p.p.m fluoride }\end{array}$ & $\begin{array}{l}\text { Diamine Silver Fluoride } 8 \% \text { solution } \\
\operatorname{Ag}\left(\mathrm{NH}_{3}\right) 2 \mathrm{~F} \\
2.2 \mathrm{mM} \mathrm{CaCl} 2 \text {, } \\
2.2 \mathrm{mM} \mathrm{NaH} 2 \mathrm{PO} 4 \text {, and } 50 \mathrm{mM} \text { acetic acid; } \\
1 \mathrm{M} \mathrm{KOH} . \mathrm{pH} 4.4 \text {. }\end{array}$ & $\begin{array}{l}\text { Generic at Department Of } \\
\text { Chemistry, faculty Of } \\
\text { Science,Suez Canal University } \\
\text { Prepared in Organic Chemistry } \\
\text { Departement, Faculty of science, } \\
\text { Suez canal University }\end{array}$ \\
\hline $\begin{array}{l}\text {-Nano Silver Fluoride particles size } \\
(3.2-1.2 \mathrm{~nm}) \\
\text { (Synthetic) }\end{array}$ & $\begin{array}{l}\text { - } \text { Chitosan }(28,585 \mu \mathrm{g} / \mathrm{ml}) \text {; } \\
\text { - Silver }(376.5 \mu \mathrm{g} / \mathrm{ml}) \text {; } \\
\text { - Sodium fluoride }(5028.3 \mu \mathrm{g} / \mathrm{ml})\end{array}$ & Generic at Nanotech Egypt lab. \\
\hline $\begin{array}{l}\text {-Artificial saliva } \\
\text { saliva }\end{array}$ & $\begin{array}{l}1.5 \mathrm{mmol} / \mathrm{L} \mathrm{Ca} \mathrm{Cl} 2,50 \mathrm{mmol} / \mathrm{L} \mathrm{K} \mathrm{Cl}, 0.9 \\
\mathrm{mmol} / \mathrm{L} \mathrm{K} \mathrm{H} 2 \mathrm{Po} 4 \text { and } \mathrm{mmol} / \mathrm{L} \text { Tris buffer } \\
\text { at } \mathrm{pH} \text { of } 7.3\end{array}$ & $\begin{array}{l}\text { Prepared in Organic Chemistry } \\
\text { Departement, Faculty of science, } \\
\text { Suez canal University }\end{array}$ \\
\hline -Disc & $\begin{array}{l}\text { SiC abrasive paper 800_2400(Silicon } \\
\text { Carbide Grinding Disc abrasive paper) }\end{array}$ & $\begin{array}{l}\text { Grit; struers, Copenhagen, } \\
\text { Denmark }\end{array}$ \\
\hline
\end{tabular}

\section{II -Methods:}

\section{II-1-Sample size calculation}

Sample size calculation was performed using $\mathbf{G}$

\section{Power version 3.1.9.2 ${ }^{(16)}$}

The effect size was 0.77 using alpha $(\alpha)$ level of 0.05 and Beta $(\beta)$ level of 0.05 , i.e., power $=95 \%$; the estimated minimum sample size (n) was a total of $\mathbf{4 0}$ samples for all groups (8 samples for each group).

\section{II-2 -Sample collection}

Twenty Extracted premolars for orthodontic reasons were collected from the Outpatient Clinic of surgical Department, Faculty of Dentistry, Suez Canal University with the following inclusion criteria:

- Sound surfaces.

- Free of white spots, cracks, and other defects.

- Not restored before. 
Premolars were be stored in saline prior to preparation.

\section{II-3 -Samples, Grouping and Adaptation:}

- Each premolar was sectioned buccolingually into two halves, to obtain (40) specimens.

- They were divided into 5 groups.

Group I included 8 specimens that were left untreated and acted as a negative control group. Enamel surfaces in this group were remained intact. Specimens were stored in artificial saliva for 7 days at $37^{\circ} \mathrm{c}$ in incubator

-The remaining specimens (32) were treated with demineralizing solution and divided into:-

Group II included 8 specimens that were treated with demineralizing solution for 1 hour three times a day, with 2- hour preservation in artificial saliva $(\mathrm{pH} 7)$ in between, this performed for 7 days at $37^{\circ}$ $\mathrm{c}$ in incubator. ${ }^{(17)}$

Group III included 8 specimens that were demineralized with demineralization procedures that were performed in group II. Then silver diamine fluoride (commercial) was applied with cotton swab for 2 minutes. Then specimens were washed with sufficient flow of deionized water for approximately 30 seconds. Finally they lightly dried with absorbent paper before being immersed in artificial saliva. They will be incubated at $37^{\circ} \mathrm{C}$ (in an incubator) for 7 days in a tightly capped container filled with artificial saliva. ${ }^{(18)}$

Group IV included 8 specimens that were demineralized with demineralization procedures that were performed in group II. Then silver diamine fluoride (lab) was applied with cotton swab for 2 minutes. Then specimens were washed with sufficient flow of deionized water for approximately 30 seconds. Finally they lightly dried with absorbent paper before being immersed in artificial saliva. They will be incubated at $37^{\circ} \mathrm{C}$ (in an incubator) for 7 days in a tightly capped container filled with artificial saliva.
Group V included 8 specimens that were demineralized with demineralization procedures that were performed in group II. Then Nano silver fluoride was applied with cotton swab for 2 minutes. Then specimens were washed with sufficient flow of deionized water for approximately $30 \mathrm{sec}-$ onds. Finally they lightly dried with absorbent paper before being immersed in artificial saliva. They will be incubated at $37^{\circ} \mathrm{C}$ (in an incubator) for 7 days in a tightly capped container filled with artificial saliva. ${ }^{(19)}$

\section{II-4- Methods of Assessments:}

\section{1- Enviromental scanning electron microscope (ESEM):}

All Samples of groups (I, II, III, IV and V) were taken out from artificial saliva for 2 hours to dry before analysis then, they were examined using environmental scanning electron microscope (QUANTA FEG-250) to observe ultra-morphology of enamel surfaces.

\section{2- Energy dispersive x-ray spectroscopy (EDX):}

Samples of groups (I, II, III, IV and V) were also subjected to energy dispersive $\mathrm{x}$ - ray spectroscopy to measure minerals content (calcium, Phosphorus and fluoride)

\section{III- Statistical analysis:}

All data was calculated, tabulated and statistically analyzed using suitable statistical tests as follow.

A normality test was done to check normal distribution of the sample, and all groups and must be showed normal distributions.

One way ANOVA was used to compare between the five groups for each element under study and Tukey test was used as post hoc to compare mean differences at significant level ( $\mathrm{P}$ value). 0.05 . Statistical analysis was performed using the computer program SPSS software for windows version 22.0 (Statistical Package for Social Science, 
Armonk, NY: IBM Corp) at significant levels 0.05 (P- Value $\leq 0.5$ ).

\section{RESULTS}

\section{1- Enviromental scanning electron microscopic} (ESEM) results:

\section{- Group I (negative control group):}

SEM evaluation of the negative control group revealed circumferentially arranged enamel rods (heads) with inter rod material (tails) producing a typical key hole appearance (Fig. 1).

\section{- Group II (demineralization group):}

Examination of the specimens that were treated with demineralizing solution revealed well- defined apatitic-like crystals with intermittent interstices. The surface structure of enamel was porous, with larger inter crystalline spaces. Furthermore, demineralization increases the surface area and creates new sites in enamel. This was accompanied by partial loss of normal key hole enamel pattern. (Fig. 2).

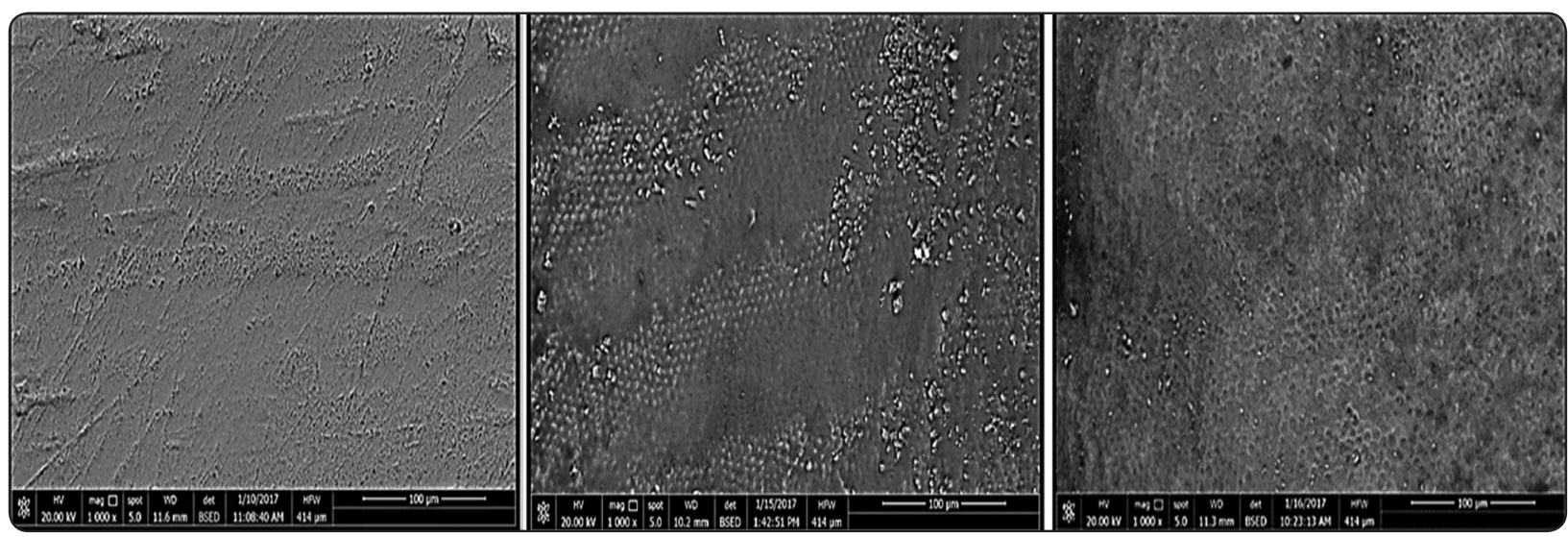

Fig. (1): SEM photographs of Group I (negative control) exhibited circumferentially arranged enamel rods and inter rod material with characteristic key hole pattern. (Magnification 1000X).
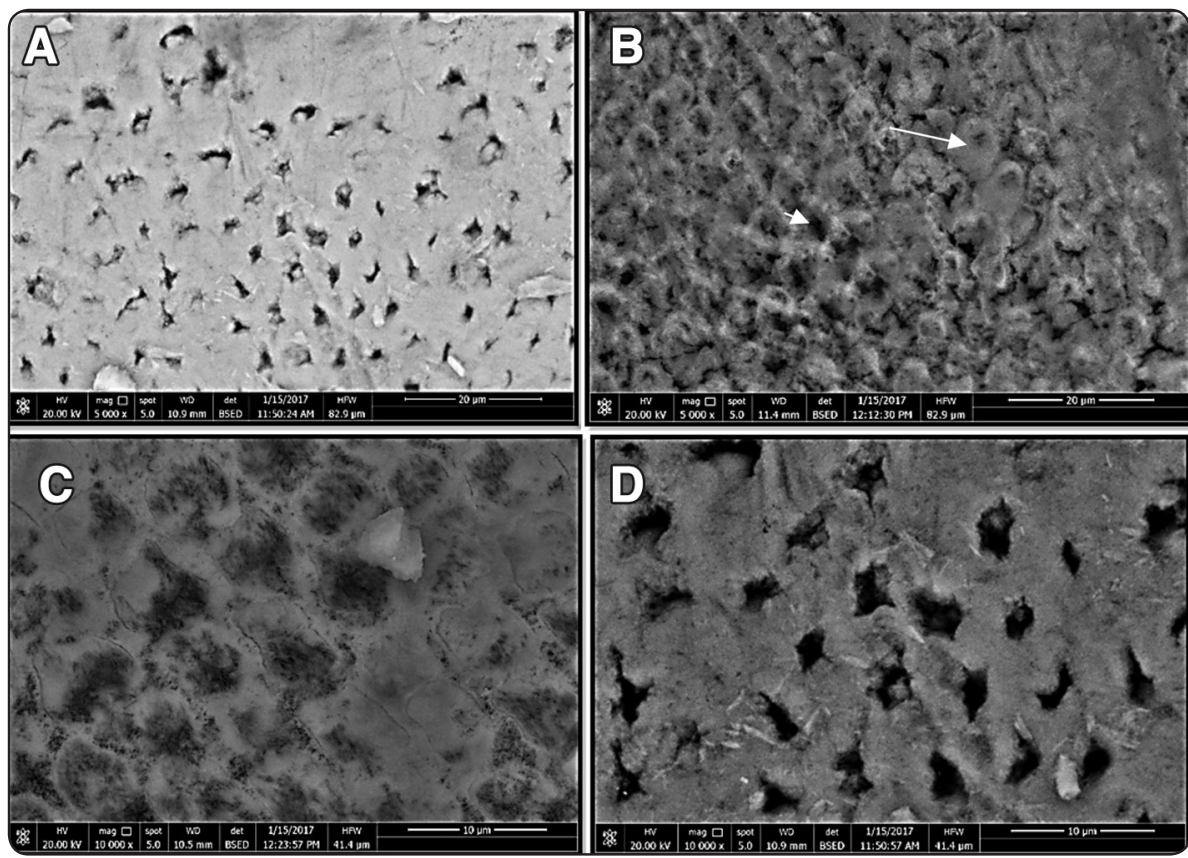

Fig. (2) (A), (B) SEM photographs of Group II revealing well- defined apatitic-like crystals (arrow) alternating with crevices (arrow head) (magnification 5000X). (C) (D) SEM photographs of Group II revealing higher magnifications of (A, B) (magnification 10000X). 
- Group III (commercial- form silver diamine fluoride group)

The SEM images showed apparent decrease in number of gaps between crystals with formation of new small separate crystals distributed over the surface and partial regain of the characteristic key hole appearance when compared to group II (demineralization group) (Fig. 3).

\section{- Group IV (lab- made silver diamine fluoride group) :}

SEM examination of this group specimens revealed the incorporation of SDF particles into the fissures and crevices previously created by demineralizing solution and partial occlusion of these fissures (Fig. 4).

\section{- Group V ( Nano silver fluoride) group:}

Specimens of this group characterized by regaining almost the normal architecture of the electron microscopic structure of enamel. By the obvious precipitation of NSF particles on the circumference of the enamel prism (prism sheath) together with the interprismatic substance, the typical key hole pattern was back again. (Fig. 5).


Fig. (3) (A) (B) SEM photographs of Group III revealing fewer number of gaps between crystals with formation of new small separate crystals (arrows) (magnification 5000X).
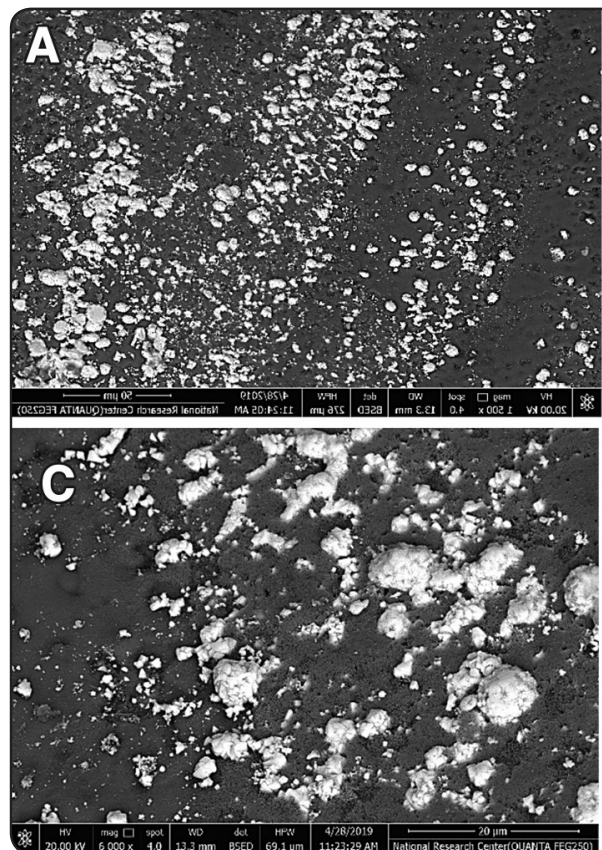

Fig. (4) (A), (B) SEM photographs of Group IV revealing SDF particles that are incorporated into the demineralized enamel surface (magnification 1500X, 3000X respectively). (C), (D) SEM photographs of Group IV showing higher magnifications of (A), (B) revealing the shape of SDF particles (magnification $6000 \mathrm{X}, 12000 \mathrm{X}$ respectively). 

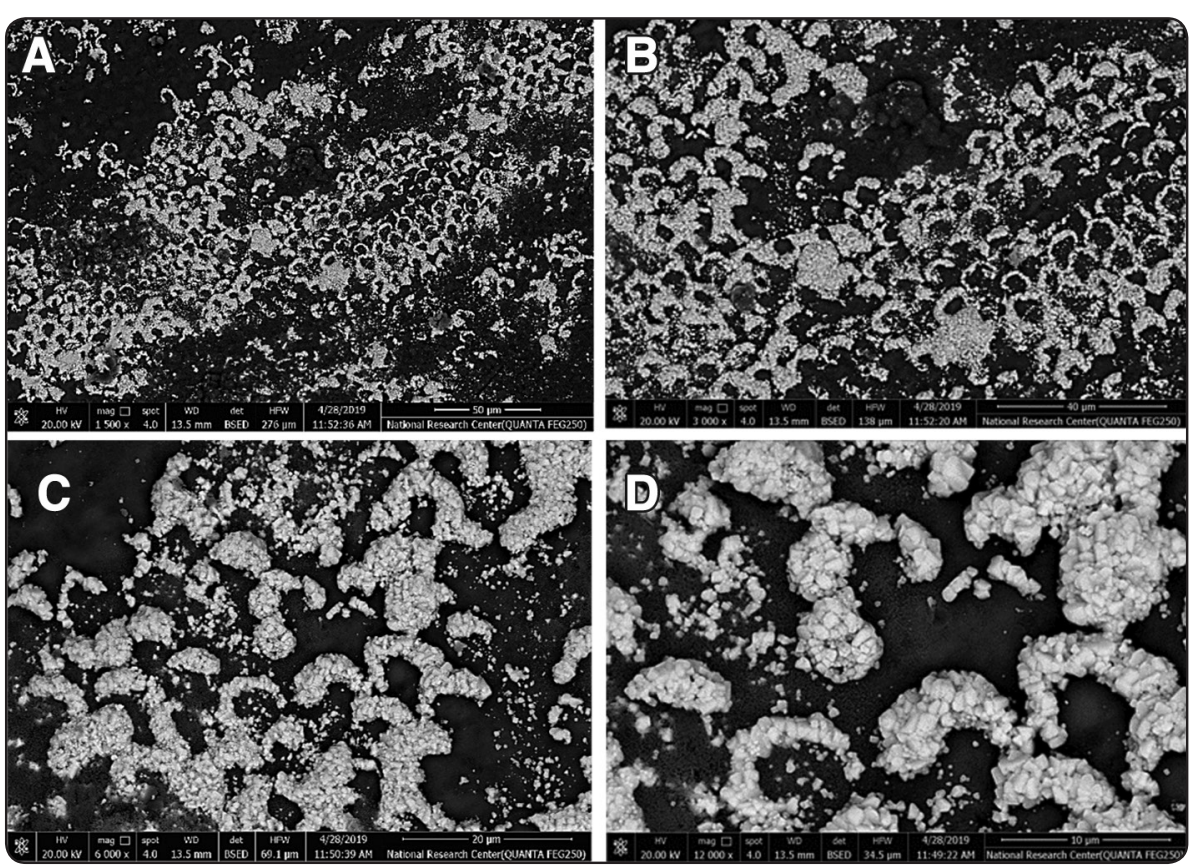

Fig. (5) (A), (B) SEM photographs of Group V revealing precipitation of NSF particles on the circumference of the enamel prism (prism sheath) (magnification 1500X, 3000X respectively). (C), (D) SEM photographs of Group V showing higher magnifications of (A), (B) revealing the shape of the typical key hole pattern (magnification 6000X, $12000 X$ respectively).
2-Energy dispersive x-ray spectroscopy (EDX) results

The results in table 1, showed significant differences between groups at $\mathrm{P}$-value 0.05 for $\mathbf{P}$, $\mathbf{C a}$ and $\mathbf{C a} / \mathbf{P}$ ratio except $(\mathbf{F})$. The lowest value for F element was recorded in group (II) followed by group (I) and the highest value was recorded at group (V). For (P) element the highest values were recorded in group (V) and group (IV), while the lowest value was recorded in group (II). For (Ca) and the highest value was recorded in $\operatorname{group}(\mathbf{V})$. $\mathbf{C a} / \mathbf{P}$ for all groups :- The group(II) is considered the lowest group for this ratio 1.83 followed by Group(IV).

Table (2): illustrates mean values for Calcium (Ca), Phosphorous (P), Fluoride (F) weights \% and Calcium: Phosphorus ratio (Ca:P ratio) of the five groups

\begin{tabular}{|c|c|c|c|c|c|}
\hline \multirow{2}{*}{ Groups } & $\mathbf{F}$ & $\mathbf{P}$ & $\mathbf{C a}$ & Ca/P & Ca/P\% \\
\cline { 2 - 6 } & Mean \pm SD & Mean \pm SD & Mean \pm SD & Mean \pm SD & Mean \pm SD \\
\hline Control & $1.91 \pm 0.60^{\mathrm{a}}$ & $14.00 \pm 0.69^{\mathrm{a}}$ & $31.30 \pm 2.24^{\mathrm{b}}$ & $2.24^{\mathrm{ab}}$ & $224.00^{\mathrm{ab}}$ \\
\hline Dem & $1.27 \pm 0.10^{\mathrm{a}}$ & $7.66 \pm 3.37^{\mathrm{b}}$ & $12.83 \pm 1.11^{\mathrm{c}}$ & $1.83^{\mathrm{c}}$ & $183.00^{\mathrm{c}}$ \\
\hline SDF com made & $2.28 \pm 0.85^{\mathrm{a}}$ & $13.89 \pm 2.16^{\mathrm{a}}$ & $28.89 \pm 2.6^{\mathrm{b}}$ & $2.09^{\mathrm{bc}}$ & $209.00^{\mathrm{bc}}$ \\
\hline SDF lab made & $2.51 \pm 1.02^{\mathrm{a}}$ & $14.72 \pm 0.83^{\mathrm{a}}$ & $28.96 \pm 1.63^{\mathrm{b}}$ & $1.97^{\mathrm{bc}}$ & $197.00^{\mathrm{bc}}$ \\
\hline NSDF & $2.95 \pm 0.54^{\mathrm{a}}$ & $14.94 \pm 2.19^{\mathrm{a}}$ & $35.41 \pm 3.50^{\mathrm{a}}$ & $2.41^{\mathrm{a}}$ & $241.00^{\mathrm{a}}$ \\
\hline P- value0.05 & $0.16 n s$ & $0.000^{* *}$ & $0.000^{* *}$ & $0.000^{* *}$ & $0.000^{* *}$ \\
\hline
\end{tabular}

**, and different letters at the same column means significant difference between groups at P-value $<0.05$. 


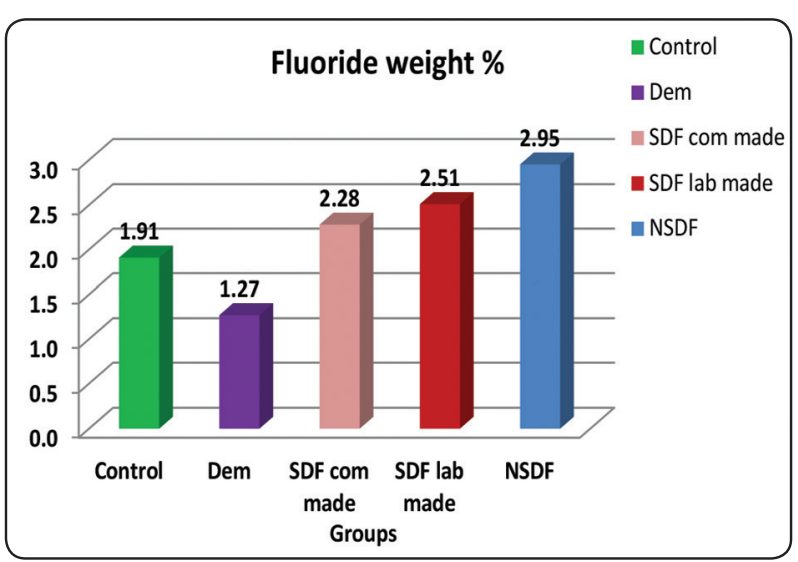

Fig. (6): Showing the mean values for Fluoride weight $\%$ of the five groups.

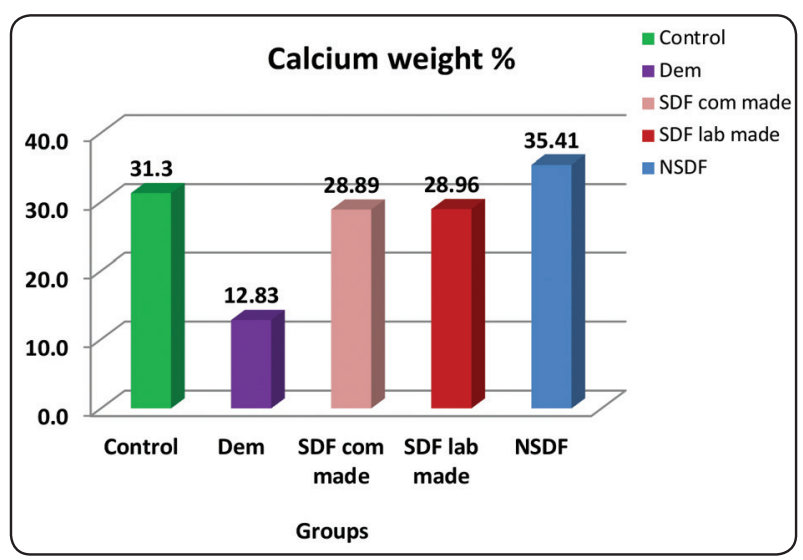

Fig. (8): Showing the mean values for Calcium weight $\%$ of the five groups.

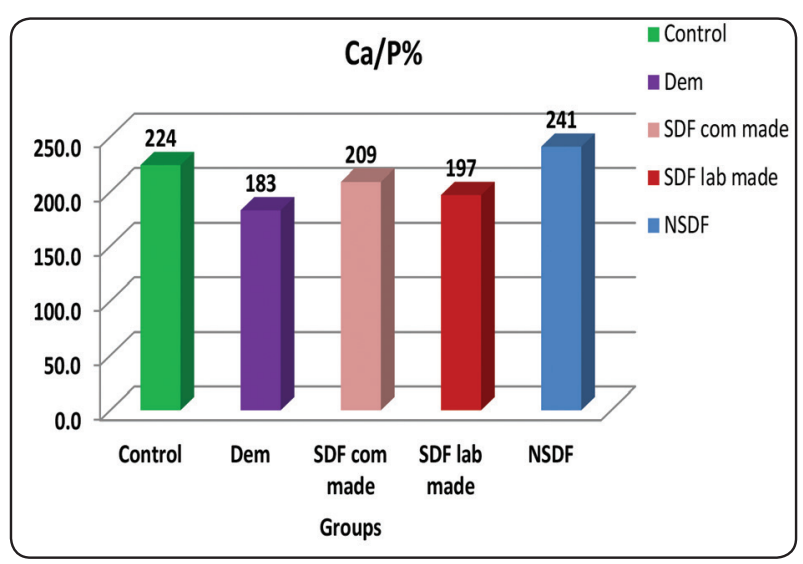

Fig. (10): Showing the mean values for Calcium/Phosphorus weight $\%$ of the five groups.

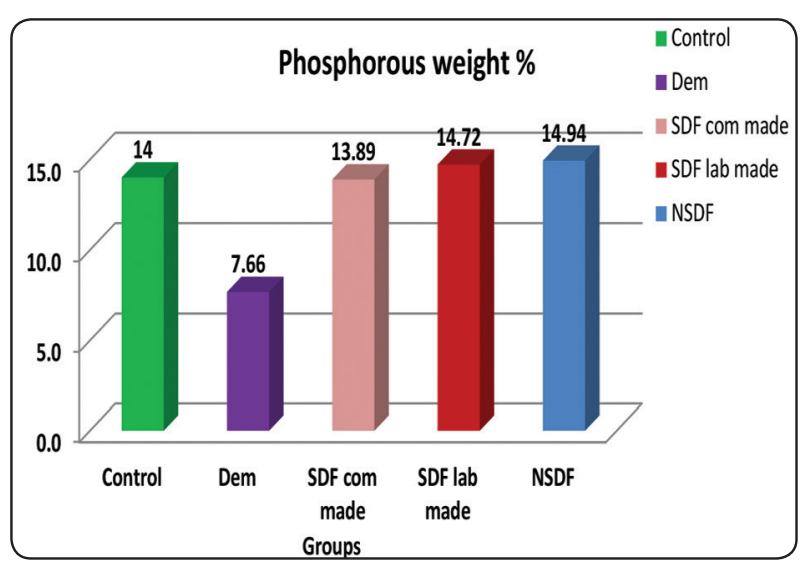

Fig. (7): Showing the mean values for Phosphorous weight $\%$ of the five groups.

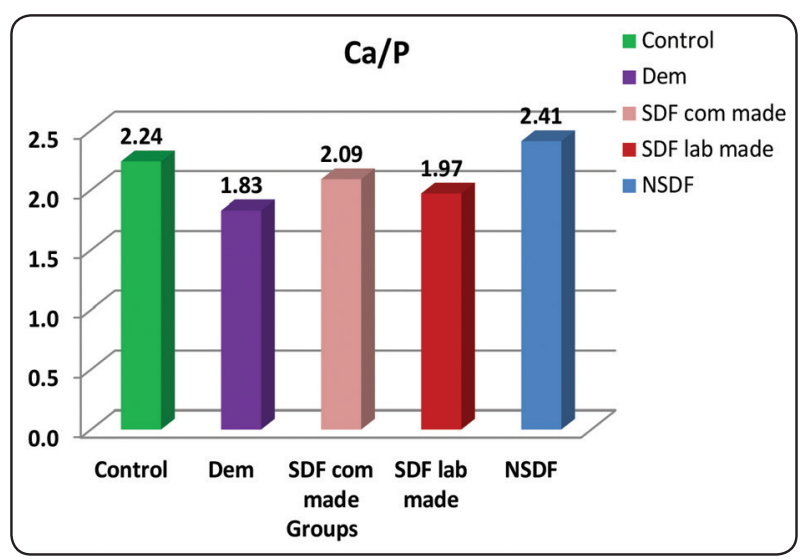

Fig. (9): Showing the mean values for Calcium/Phosphorus of the five groups.

\section{DISCUSSION}

The present study was conducted to compare the effects of SDF (commercial \& lab made) versus NSF on demineralized enamel surface. SDF is used to arrest dental caries in primary teeth and prevent pit and fissure caries in permanent molars accordance to Yamaga and Yokomizo ${ }^{(20)}$.

Lab made SDF was prepared in the laboratory to reduce the purchase order from abroad and also to reduce the cost and time. No chemical or physical especially color and odour were observed for 12 months at room temperature . 
NSF has been used due to its efficiency in stopping caries progression. ${ }^{(21)}$ In addition use of silver nanoparticles in adhesives, composites, cements, and sealants inhibits biofilms and increase remineralization also, NSF was freshly prepared, had the advantage of not staining the dental tissue black, do not form oxides when reacts with oxygen in the medium and had no metallic taste as occurs in sodium fluoride treatment ${ }^{(22)}$.

In this study, premolars have been freshly extracted from patients (12-14) years old for standardization and free from any aging changes that may present in enamel surfaces.All premolars were selected free from caries and any anatomical and morphological anomalies or structural abnormality such as enamel hypoplasia, amelogenesis imperfecta which can affect scanning Electron microscope results ${ }^{(23)}$. Specimens were stored in normal saline at room temperature to prevent dehydration.

$\mathrm{PH}$ cycling was performed to simulate caries challenge for 7 days this is in agreement with Vieira et al ${ }^{(17)}$. This disagrees with Mohammadi and Farahmand $^{(23)}$ who performed Demineralization cycle and repeated daily for 5 days then remineralization cycle for 2 days.

The null hypothesis was rejected, The results of scanning Electron microscope showed decrease in numbers of gaps with closure of fissures in NSDF treated group this is in accordance to Zhao et al ${ }^{(24)}$ more than the two groups treated with SDF that promotes remineralization of hydroxyapatite of enamel.

The particles of NSF precipitated on the demineralized enamel with regaining of normal enamel architectures than SDF treated groups this may be due to small particles size $(3.2-1.2 \mathrm{~nm})$ which has high remineralization effects of Nano particles. On other hands, partial occlusion of fissures in demineralized enamel surfaces treated with SDF lab made more than SDF commercial made this is due to efficiency of lab made SDF on demineralized enamel surfaces.
The results of energy dispersive $x$-ray spectroscopy in this study revealed that the value of fluoride significantly increased in all groups treated with SDF and NSF treated group in comparison to demineralized group this attributed to high fluoride content in different treatments modalities groups that had remineralizing effects on demineralized enamel surfaces. This is in agreement with clinical trial which found that application of SDF and NSF had the same clinical efficiency in preventing dental caries ${ }^{(25)}$. This finding disagreed with Lee et al ${ }^{(26)}$ who studied the effect of three different topical fluoride containing agents on incipient caries and they found that fluoride didn't affect surface micro hardness of enamel.

The value of phosphorus and calcium ions significantly increased in groups treated with lab made SDF and commercial SDF in comparison to control and demineralized groups this is accordance to an ex vivo study that reported hard remineralized layer rich with calcium and phosphate was performed after application of $\mathrm{SDF}^{(27) .}$

Moreover NSF treated group showed significant increase in calcium and phosphorus ions in comparison to control and demineralized enamel groups this may be due to effects of Nano particles in increasing deposition of these ions on demineralized enamel surfaces ,that in accordance with Ata Mostafa ${ }^{(28)}$.

Calcium / Phosphorus ratio and Calcium Phosphorus percentage significantly increased in NSF treated group in comparison to all treated groups this due to efficiency of small particles of Nano silver in remineralizing enamel surfaces ${ }^{(28)}$.

\section{CONCLUSION}

1. SDF (lab made) is as efficient as commercial one in remineralizing enamel surfaces.

2. NSF is more efficient than SDF (lab made \& commercial form) on demineralized enamel surfaces.

3. The possible mechanism of action for arresting enamel carries by either SDF or NSF is inhibition of mineral loss. 


\section{ACKNOWLEDGEMENTS}

\section{Great thanks to:}

Prof. Dr. Sabry El-korashy, Professor of Inorganic Chemistry, Faculty of Science, Suez Canal University who prepared the experimental materials in this study.

All members in National Research Centre, Dokki, Egypt who assisted us in finishing this study.

\section{RECOMMENDATIONS}

1. SDF (lab made) can be used as efficient remineralizing agent.

2. NSDF can be used in arresting enamel surface caries both in vitro $\&$ in vivo.

3. Further studies should be conducted in vivo to study the effects of SDF \& NSDF on demineralized enamel and dentin.

\section{REFERENCES}

1. Somasundaram P, Vimala N and Mandke LG: Protective potential of casein phosphopeptide amorphous calcium phosphate containing paste on enamel surface .J Conserv Dent 2013;16:152-156.

2. Yadav S, Singh S, Sharma P, Thapliyal A and Gupta V: Antibiofilm formation activity of Terminalia bellerica plant extract against clinical isolates of Streptococcus mutans and Streptococcus sobrinus: implication in oral hygiene. Int J Pharm Bio Sci 2012; 3:816-821.

3. Gamboa F, Estupinan M and Galindo A: Presence of Streptococcus mutans in saliva and its relationship with dental caries: antimicrobial susceptibility of the isolates. J Conserv Dent 2004; 9:23-27.

4. Patil N, Choudhari S, Kulkarni S and Joshi SR: Comparative evaluation of remineralizing potential of three agents on artificially demineralized human enamel: an in vitro study. J Conserv Dent 2013; 16:116-120.

5. Lata S, Varghese NO and Varughese JM: Remineralization potential of fluoride and amorphous calcium phosphatecasein phospopeptide on enamel erosion: an in vitro comparative evaluation. J conserv Dent 2010; 13:42-46.

6. Ten Cate JM: In vitro studies on the the effects of fluoride on remineralization J Dent Res 1990; 69:614-619.
7. Rosen S, Min DB, Harper DS, Harper WJ, Beck EX and Beck FM: Effect of cheese, with and without sucrose, on dental caries and recovery of Streptococcus mutans in rats. J Dent Res 1984; 63:894-896.

8. Peng JJ, Botelho MG and Matinlinna JP: Silver compounds used in dentistry for caries management: a review. J Dent 2012; 40:531-541.

9. Lou YL, Botelho MG and Darvell BW: Reaction of silver diamine fluoride with hydroxyapatite and protein. $\mathrm{J}$ of Dent. 2011; 39:612-618.

10. Horst JA, Ellenikiotis H and Milgrom PL: UCSF protocol for caries arrest using silver diamine fluoride: Rationale, indications and consent. J Calif Dent Assoc 2016; 44:16-28.

11. Kreth J, Kim D, Nguyen M, Hsiao G, Mito R, Kang MK: The antimicrobial effect of silver ion impregnation into endodontic sealer against Streptococcus mutans. Open dent j. 2007; 2:18-23

12. Chu CH, Lo ECM, Lin HC: Effectiveness of silver diamine fluoride and sodium fluoride varnish in arresting dentin caries in Chinese pre-school children. J. of dent. res. 2002; 81(11):767-770.

13. Mei ML, Ito L, Cao Y, Li QL, Lo ECM, Chu CH: Inhibitory effect of silver diamine fluoride on dentine demineralisation and collagen degradation. J. of dent. 2013; 41(9):809-817.

14. Nozari A, Ajami SH, Rafiei A, Niazi El: Impact of nano hydroxyapatite, nano silver fluoride and sodium fluoride varnish on primary teeth enamel remineralization: an in vitro study. J of clin. and diag res.2017; 11(9): 97-100.

15. Konishi N, Fried D, Staninec M, and Featherstone JD: Artificial caries removal and inhibition of artificial secondary caries by pulsed CO2 laser irradiation. Am. $\mathrm{j}$ of dent. 1999; 12(5):213-216.

16. Faul, F., Erdfelder, E., Lang, A.-G., \& Buchner, A.: $\mathrm{G}^{*}$ Power 3: A flexible statistical power analysis program for the social, behavioral, and biomedical sciences. Beh. Res. Meth. (2007) 39, 175-191.

17. Vieira AE, Delbem AC, Sassaki KT, Rodrigues E, Cury JA, Cunha RF, et al. Fluoride dose response in pH-cycling models using bovine enamel. Caries Res 2005; 39:514-20.

18. Alberto Carlos, Botazzo Delbem, Maurício Bergamaschi, Kikue Takebayashi Sassaki, Robson Frederico Cunha: Effect of fluoridated varnish and silver diamine fluoride solution on enamel demineralization: ph-cycling study, 
J Appl Oral Sci. 2006 Apr; 14(2): 88-92. doi: 10.1590/ S1678-77572006000200005 PMCID: PMC4327448

19. Santos VE Jr, Vasconcelos Filho A, Targino AG, Flores MA, Galembeck A, Caldas AF Jr, et al. A new "silverbullet" to treat caries in children--nano silver fluoride: a randomized clinical trial. J Dent. 2014; 42:945-51.

20. Yamaga R, Yokomizo I. Arrestment of caries of deciduous teeth with diamine silver fluoride. Dent Outlook 1969; 33: 1007-1013.

21. Guimarães GS, Morais LS, Elias CN, Pérez CAC, Bolognese AM: Chemical and morphological analysis of the human dental enamel treated with argon laser during orthodontic bonding .Dental Press J Orthod , 2011 MarApr;16(2):100-7.

22. Zhang Q, Zou J, Yang R, Zhou X. Remineralization effects of casein phosphopeptide-amorphous calcium phosphate crème on artificial early enamel lesions of primary teeth. Int J Paediatr Dent 2013; 21:374-381.

23. Mohammadi N, Farahmand Far MH. Effect of fluoridated varnish and silver diamine fluoride on enamel demineral- ization resistance in primary dentition. J Indian Soc Pedod Prev Dent. 2018; 36:257-61.

24. Zhao IS, Gao SS, Hiraishi N, Burrow MF, Duangthip D, Mei ML, Lo EC and Chu CH. Mechanisms of silver diamine fluoride on arresting caries: a literature review. International Dental Journal. 2018; 68: 67-76.

25. Tirupathi S, SVSG N, Rajasekhar S, Nuvvula S. Comparative cariostatic efficacy of a novel Nano-silver fluoride varnish with $38 \%$ silver diamine fluoride varnish a double-blind randomized clinical trial. J Clin Exp Dent. 2019; 11(2):e105-12.

26. Lee YE, Baek HJ, Choi YH, Jeong SH, Park YD, Song $\mathrm{KB}$, et al. Comparison of remineralization effect of three topical fluoride regimens on enamel initial carious lesions. J Dent 2010; 38:166-71.

27. Mei ML, Ito L, Cao Y et al. An ex vivo study of arrested primary teeth caries with silver diamine fluoride therapy. $\mathrm{J}$ Dent. 2014 42: 395-402.

28. Ata Mostafa: Influence of Nano-silver fluoride, Nano -hydroxyapatite and casein phosphopeptide - amorphous calcium phosphate on microhardness of bleached enamel: in-vitro study S.M., Tanta Dental J 2019,16(1):25-28. 